\title{
Asymmetric Intramolecular Diels-Alder Reactions of Trienals Catalyzed by Chiral Ruthenium Lewis Acids
}

\author{
Sirinporn Thamapipol§ and E. Peter Kündig* \\ §SCS DSM Prize for best poster
}

\begin{abstract}
Chiral single-point binding ruthenium Lewis acid catalysts [Ru(acetone)((S,S)-BIPHOP-F)(Cp)][SbF $F_{6}$ $((S, S)-1 \mathrm{a})$ and $\left[\mathrm{Ru}(\right.$ acetone) $)((S, S)-\mathrm{BIPHOP}-\mathrm{F})($ indenyl) $]\left[\mathrm{SbF}_{6}\right]((\mathrm{S}, S)-\mathbf{1 b})$ efficiently catalyze intramolecular DielsAlder (IMDA) reactions of trienals under mild conditions to afford the endo cycloaddition products as the major products in good yields with high diastereo- and enantioselectivities.
\end{abstract}

Keywords: Asymmetric IMDA reaction - Chiral catalyst · Diels-Alder · Lewis acid · Ruthenium

Cycloaddition reactions with their potential for a high degree of stereo- and regiocontrol are arguably the most versatile processes for the construction of five- and six-membered rings. Spectacular asymmetric versions have been achieved by using chiral Lewis acid catalysts. ${ }^{[1]}$ Our studies in this area focused on one-point binding chiral ruthenium Lewis acids (1a and $\mathbf{1 b})$ that are based on structurally well-defined monocationic half-sandwich complexes that incorporate a $C_{2}$-symmetric perfluoroaryl phosphinite ligand. This ligand enforces the appropriate chiral environment around the coordination site and it also offsets the donor properties of the cyclopentadienyl- and indenyl-ligands (Fig. 1). The chiral, electron-poor ligand contributes to the Lewis acidity of these complexes, and together with the aromatic arene, generate a chiral binding site that is ideal for the activation of $\alpha, \beta$-unsaturated carbonyl compounds.

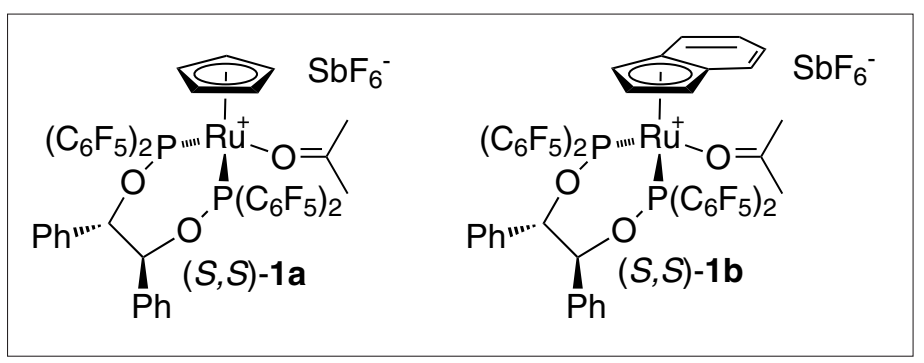

Fig. 1. Single-point binding chiral Ru Lewis acid catalysts.

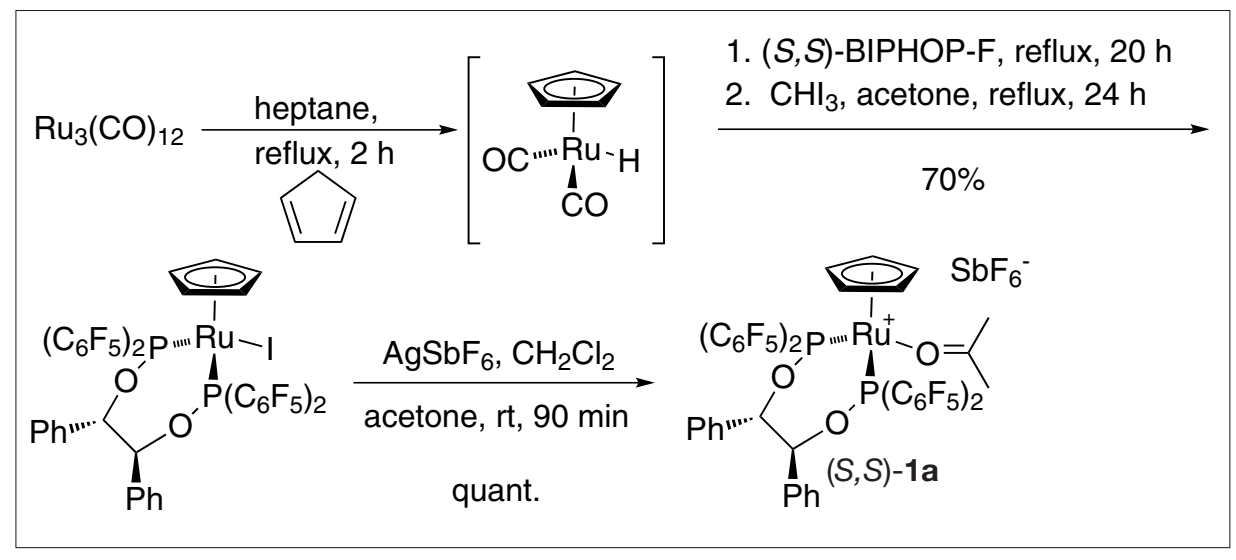

Scheme 1. Synthesis of $\left[\mathrm{Ru}\left(\right.\right.$ acetone)((S,S)-BIPHOP-F)(Cp)][SbF$\left.{ }_{6}\right](\mathbf{1 a})$.

The synthesis of the stable iodoruthenium complex was achieved in a 'one pot' procedure from $\left[\mathrm{Ru}_{3}(\mathrm{CO})_{12}\right]$. Significant to the success was the hydride-labilizing effect, which enabled $\mathrm{CO}$ substitution in the in situ formed $\left[\mathrm{RuCp}(\mathrm{CO})_{2} \mathrm{H}\right]$. Heating at reflux in acetone in the presence of iodoform afforded the chiral Ru-iodo complex, and halide abstraction by $\mathrm{AgSbF}_{6}$ generated Lewis acid 1a as shown in Scheme 1.[2a]

Catalyst 1b was synthesized via ligand exchange in $\left[\mathrm{Ru}(\mathrm{Cl})(\right.$ indenyl $\left.)\left(\mathrm{PPh}_{3}\right)_{2}\right]$ with BIPHOP-F to afford [Ru(BIPHOP-F) $(\mathrm{Cl})$ (indenyl)]. Halide abstraction with $\mathrm{AgSbF}_{6}$ furnished Lewis acid $\mathbf{1 b}$ as shown in Scheme 2. ${ }^{[2 b]}$

These mild chiral Lewis acids proved to be excellent catalysts for intermolecular Diels-Alder (DA) reactions of various dienes with enals ${ }^{[2]}$ and enones, ${ }^{[3]}$ 1,3-dipolar cycloadditions of enals with nitrones ${ }^{[4]}$ and of enals with nitrile oxides ${ }^{[4 b, 5]}$ as shown in Scheme 3. The 1,4-addition of thiophenols to enones could also be carried out using these catalysts. ${ }^{[6]}$ Representative examples are shown in Scheme 4.

We have established details of the mode of action of these catalysts, notably the role 


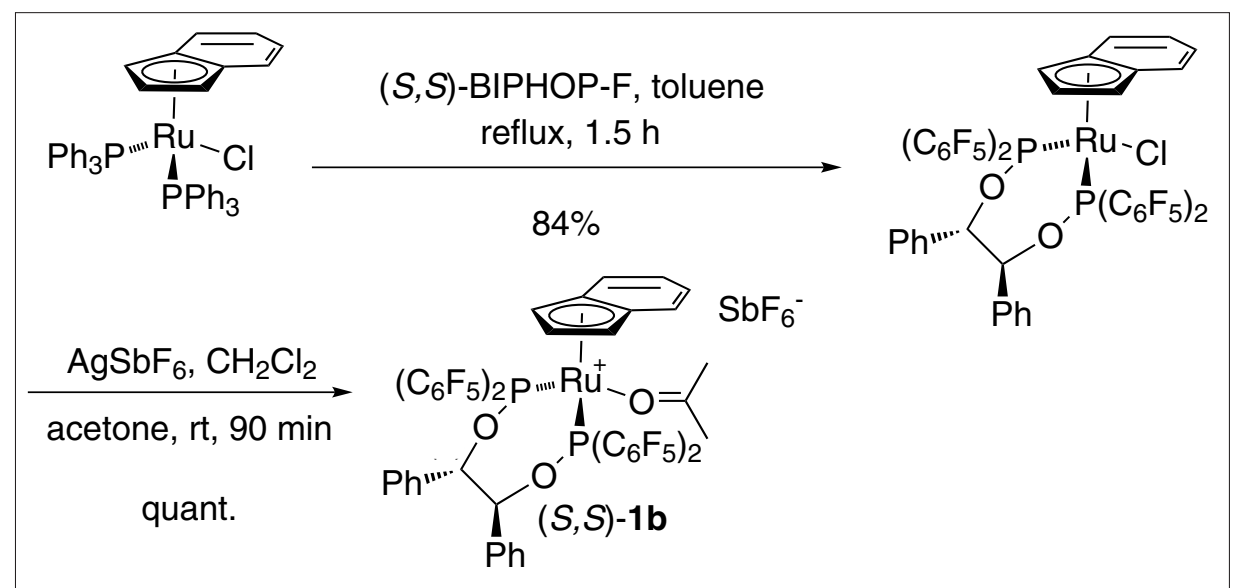

Scheme 2. Synthesis of $\left[\mathrm{Ru}(\right.$ acetone) $)((\mathrm{S}, \mathrm{S})-\mathrm{BIPHOP}-\mathrm{F})\left(\right.$ indenyl $\left.^{\prime}\right)\left[\mathrm{SbF}_{6}\right]$ (1b).

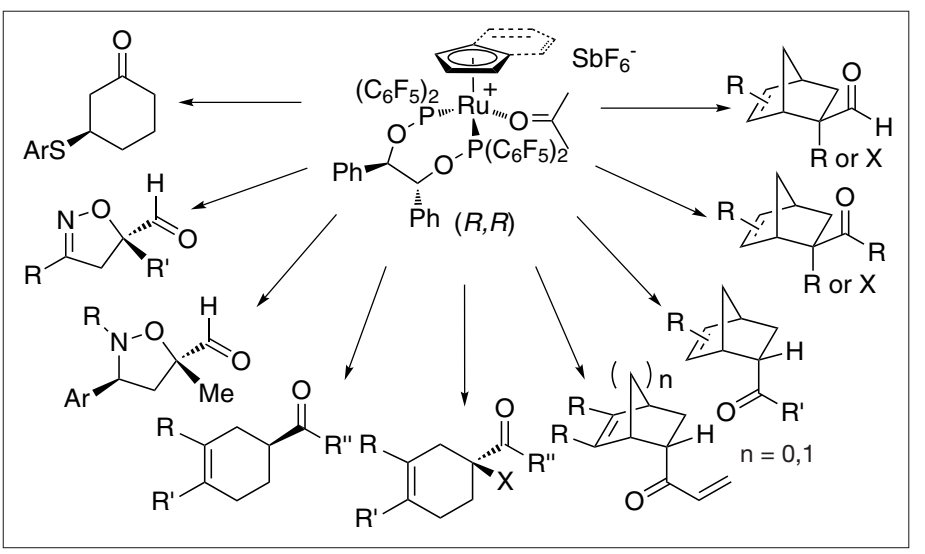

Scheme 3.

Applications.<smiles>C=C(C)C=O</smiles>

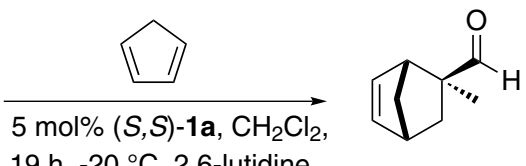

$100 \%$ conv. $92 \%$ yield

$19 \mathrm{~h},-20^{\circ} \mathrm{C}, 2,6$-lutidine

$92 \%$ ee

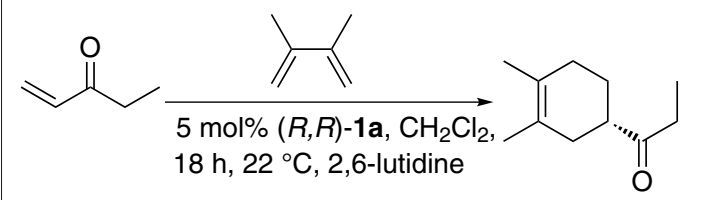

$99 \%$ conv. $76 \%$ yield $91 \%$ ee

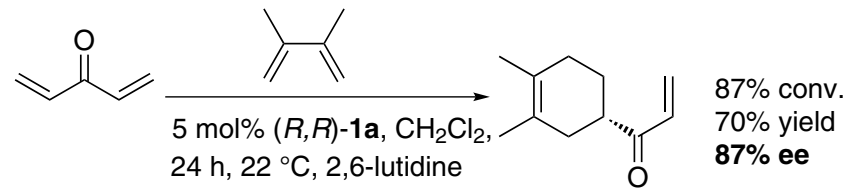

\section{ref. [3]}

ref. [3]

ref. [2a]

$22^{\circ} \mathrm{C}, 2,6$-lutidine<smiles>O=C1C=CCCC1</smiles><smiles>COc1cccc(C)c1S</smiles><smiles>O=C1CCC[C@H]([AsH2])C1</smiles>

$100 \%$ conv

$95 \%$ yield

$87 \%$ ee MS $4 \AA, \mathrm{CH}_{2} \mathrm{Cl}_{2}$<smiles>C=C(C)C=O</smiles><smiles>[H][R](C)([O-])Cc1ccc(Br)cc1</smiles><smiles>CN1O[C@@](C)(C=O)C[C@H]1c1ccc(Br)cc1</smiles>

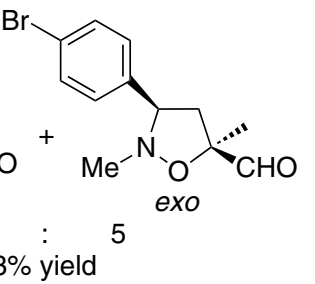

$73 \%$ yield

$\mathbf{9 7 . 7 \%}$ ee of endo-isomer of the counteranion, $[2 \mathrm{c}, \mathrm{d}]$ the pendulum motion in the $\mathrm{Ru}(\mathrm{BINOP}-\mathrm{F})$ fragment, ${ }^{[2 \mathrm{e}]}$ the competition of enals and nitrones for the Lewis acid site ${ }^{[4 \mathrm{c}]}$ and the preference of coordination of enals and vinyl ketones to the Ru-center (anti-s-trans vs syn-s-trans). ${ }^{[3]}$

To extend the application, we probed the potential of $(S, S)$-1a and $\mathbf{1 b}$ in the intramolecular Diels-Alder (IMDA) reaction. The study involved trienes 2 (Scheme 5) and 3-7 (Scheme 6) and the results of IMDA reactions of these substrates catalyzed by $(S, S)$-1a and $\mathbf{1 b}$ were investigated..$^{[3,7,8]}$ Triene $\mathbf{2}$ containing a vinyl ketone dieneophile, provided the highly enantiomerically enriched bridgehead adduct 8 in good yield. [3] Reflecting the lower reactivity of $\beta$-substituted keto-dienophiles, triene $\mathbf{5}$ failed to react. Trienals $3{ }^{[9 a, b]}$ and $4,{ }^{[9 c]}$ which were previously used in asymmetric IMDA reaction by Yamamoto, furnished the cycloadducts 9 and 10, respectively in good yields with high enantioselectivities. The Thorpe-Ingold effect from the dimethyl malonate group increased the reactivity of trienals $\mathbf{6}$ and 7 shortening reaction times, from days to hours. An X-ray structure of a derivative of 9 confirmed the tentative assignment made previously based on spectroscopic data.

The absolute configurations of products 10, 12 and 13 were assigned by comparison of the CD spectra of the SAMP-hydrazones to that derived from 9 (Scheme 7).

$\mathrm{X}$-ray structures of chiral $\mathrm{Ru}$ Lewis acid/substrate complexes have been instrumental for the interpretation of observed selectivities in cycloaddition reactions. ${ }^{[2-6]}$ For the IMDA reaction involving triene 3 the diene approach leading to the observed endo product 9 was modeled as shown in Fig. 2. It is proposed that the enal dienophile (orange) coordinates to the Ru Lewis acid in an anti-s-trans conformation and the diene (blue) approaches the $C_{\alpha}-R e$ face of the enal moiety in an endo mode. The pentafluorophenyl moiety of the $(S, S)$ BIPHOP-F ligand blocks the $\mathrm{Si}$-face (Fig. 2 ). This results in the observed product stereochemistry of 9 .

\section{Conclusion}

We have developed efficient one-point binding $\mathrm{Ru}$ Lewis acid catalysts $((S, S)-\mathbf{1 a}$ and 1b) capable to catalyze diastereo- and enantioselectively not only DA reactions, 1,3-dipolar cycloadditions and Michael additions but also IMDA reactions. This method gives access to highly enantiomerically enriched bicyclic products of potential use in organic synthesis.

\section{Acknowledgment}

Financial support from the Swiss National Science Foundation and the University of Geneva is gratefully acknowledged. 


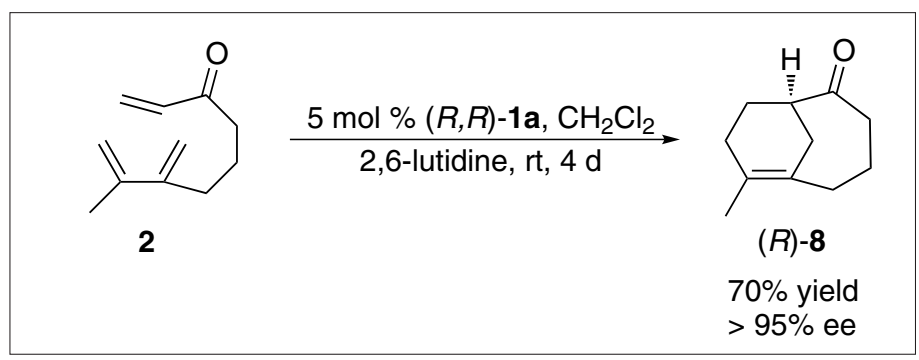

Scheme 5. IMDA reaction of triene 2 with Ru catalyst $\mathbf{1 a}$.<smiles>[R]C=C/C=C\CC([Z])([Z])CC=C([R])[R]</smiles>

4: $R=R^{1}=Z=H, R^{2}=M e$

5: $R=M e, R^{1}=R^{2}=Z=H$

6: $R=R^{2}=H, R^{1}=M e, Z=C_{2} M e$

7: $R=R^{1}=R^{2}=H, Z=\mathrm{CO}_{2} \mathrm{Me}$
3: $\mathrm{R}=\mathrm{R}^{1}=\mathrm{R}^{2}=\mathrm{Z}=\mathrm{H}$

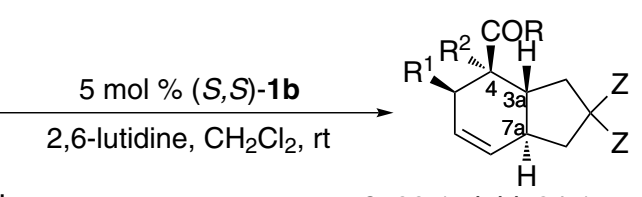

9: $92 \%$ yield, $84 \%$ ee, $99: 1$ of endo:exo 10: $85 \%$ yield, $84 \%$ ee, $81: 19$ of endo:exo 11: low yield and selectivity

12: quant., $56 \%$ ee, $99: 1$ of endo:exo 13: quant., $84 \%$ ee, $99: 1$ of endo:exo
Scheme 6. Asymmetric IMDA reactions catalyzed by $(S, S)-\mathbf{1 b}$ (catalyst $(S, S)-\mathbf{1 a}$ was less active, except in the case of triene 4). ${ }^{\left[{ }^{[]}\right.}$

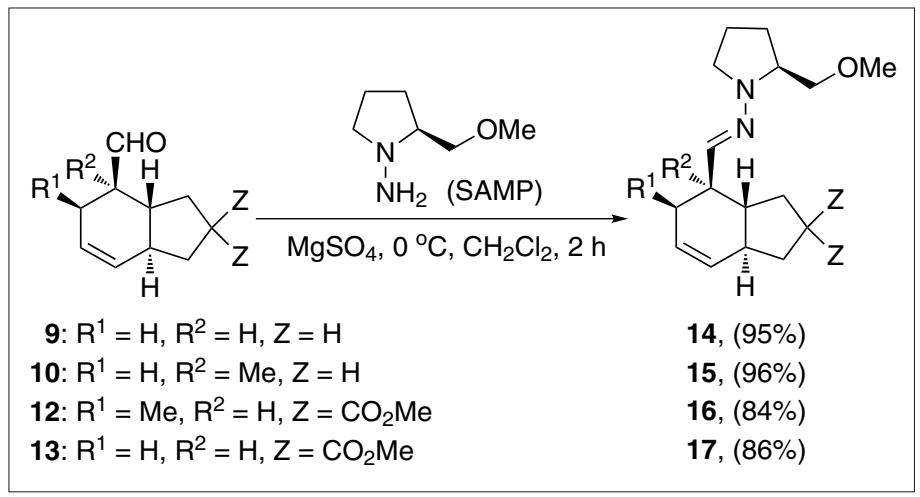

Scheme 7. Synthesis of hydrazones 14-17.

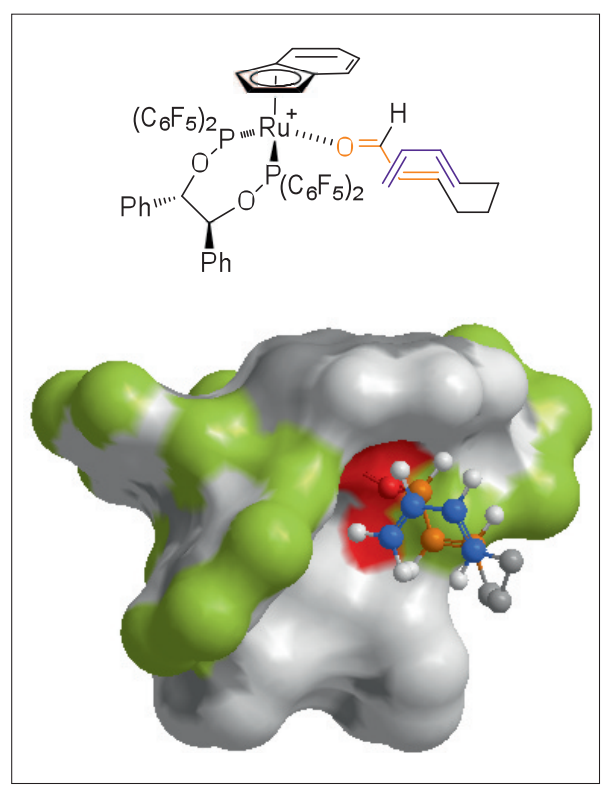

Fig. 2. Modelled approach of trienal 3 coordinated to $\mathrm{Ru}$ in $(\mathrm{S}, \mathrm{S})$-1 $\mathbf{b}$ in an anti-s-trans orientation (catalyst part taken from the X-ray structure of $[R u($ acetone $)((S, S)-B I P H O P-F)$ (indenyl)][ $\left.\mathrm{SbF}_{6}\right]((\mathrm{S}, S)-\mathbf{1 b})$.[2] $^{[\mathrm{T}}$ This model rationalizes the product's $(3 a R, 4 R, 7 a S)$ configuration.
[1] a) 'Chiral Lewis Acid: Lewis Acids and Bases, Asymmetric Synthesis, Enantiomer, Asymmetric Induction, Lithium, Zinc, Aluminium, Boron, Diol, Racemic Mixture, Diels-Alder Reaction, Hydrocyanation, Ene Reaction', Eds. F. P. Miller, A. F. Vandome, J. McBrewster, Alphascript Publishing, 2010; b) S. Reymond, J. Cossy, Chem. Rev. 2008, 108, 5359; c) J. Shen, C.-H. Tan, Org. Biomol. Chem. 2007, 6, 3229; d) E. J. Corey, Angew. Chem. Int. Ed. 2002, 41, 1650; e) 'Lewis acids in Organic synthesis' Ed. H. Yamamoto, Wiley-VCH, Weinheim, 2000, vol.1.

[2] a) E. P. Kündig, C. M. Saudan, G. Bernardinelli, Angew. Chem. Int. Ed. 1999, 38, 1220; b) E. P. Kündig, C. M. Saudan, V. Alezra, F. Viton, G. Bernardinelli, Angew. Chem. Int. Ed. 2001, 40, 4481; c) P. G. A. Kumar, P. S. Pregosin, M. Vallet, G. Bernardinelli, R. F. Jazzar, F. Viton, E. P. Kündig, Organometallics 2004, 23, 5410; d) E. P. Kündig, C. M. Saudan, F. Viton, $A d v$. Synth. Catal. 2001, 343, 51; e) V. Alezra, G. Bernardinelli, C. Corminboeuf, U. Frey, E. P. Kündig, A. E. Merbach, C. M. Saudan, F. Viton, J. Weber, J. Am. Chem. Soc. 2004, 126, 4843; f) M. E. Bruin, E. P. Kündig, Chem. Commun. 1998, 2635; g) E. P. Kündig, B. Bourdin, G. Bernardinelli, Angew. Chem. Int. Ed. 1994, 33 1856.

[3] J. Rickerby, M. Vallet, G. Bernardinelli, F. Viton, E. P. Kündig, Chem. Eur. J. 2007, 13, 3354.
[4] a) A. Bădoiu, G. Bernardinelli, E. P. Kündig, Synthesis, 2010, 2207; b) A. Bădoiu, Y. Brinkmann, $F$. Viton, E. P. Kündig, Pure. Appl. Chem. 2008, 80, 1013; c) A. Bădoiu, G. Bernardinelli, J. Mareda, E. P. Kündig, F. Viton, Chem. Asian. J. 2008, 3, 1298; d) F. Viton, G. Bernardinelli, E. P. Kündig, J. Am. Chem. Soc 2002, 124, 4969.

[5] Y. Brinkmann, R. J. Madhushaw, R. Jazzar, G. Bernardinelli, E. P. Kündig, Tetrahedron 2007, 63, 8413 .

[6] A. Bădoiu, G. Bernardinelli, C. Besnard, E. P. Kündig, Org. Biomol. Chem. 2010, 8, 193.

[7] S. Thamapipol, G. Bernardinelli, C. Besnard, E. P. Kündig, Org. Lett. 2010, 12, 5604.

[8] Rac-8 was a key intermediate in the synthesis of Ledol: S. L. Gwaltney, S. T. Sakata, , K. J. Shea, J. Org. Chem. 1996, 61, 7437.

[9] a) K. Ishihara, H. Kurihara, H. Yamamoto, $J$. Am. Chem. Soc. 1998, 120, 6920; b) K. Ishihara, H. Kurihara, H. Yamamoto, J. Am. Chem. Soc. 1996, 118, 304; c) K. Furuta, A. Kanematsu, H Yamamoto, Tetrahedron Lett. 1989, 30, 7231. 